\title{
Investigation on the Influence of Weld Position on the Deformation Behavior of Welded Tube During Free Bending Process
}

Cheng Cheng

Nanjing University of Aeronautics and Astronautics

Chao Pan

Nanjing University of Aeronautics and Astronautics

Xueshan Bai

Shenyang Aircraft Corporation

Chunmei Liu

Nanjing University of Aeronautics and Astronautics

Xunzhong Guo ( $\nabla$ guoxunzhong@nuaa.edu.cn )

Nanjing University of Aeronautics and Astronautics

\section{Research Article}

Keywords: Welded tube, Free bending, Non-uniform mechanical properties, Forming quality, Numerical simulation.

Posted Date: December 6th, 2021

DOI: https://doi.org/10.21203/rs.3.rs-1135274/v1

License: (c) (1) This work is licensed under a Creative Commons Attribution 4.0 International License. Read Full License

Version of Record: A version of this preprint was published at The International Journal of Advanced Manufacturing Technology on February 19th, 2022. See the published version at https://doi.org/10.1007/s00170-022-08893-y. 


\title{
Investigation on the influence of weld position on the deformation behavior of welded tube during free bending process
}

\author{
Cheng Cheng ${ }^{1,2}$, Chao $\operatorname{Pan}^{1}$, Xueshan $\mathrm{Bai}^{3}$, Chunmei Liu ${ }^{1}$, Xunzhong Guo ${ }^{1, *}$ \\ ${ }^{1}$ College of Material Science and Technology, Nanjing University of Aeronautics and As- \\ tronautics, Nanjing 211100, P.R. China \\ ${ }^{2}$ State Key Laboratory of Digital Manufacturing Equipment and Technology, Huazhong \\ University of Science and Technology, Wuhan 430074, P. R. China \\ ${ }^{3}$ Shenyang Aircraft Corporation, Shenyang 110850, P. R. China \\ *Corresponding author. E-mail address: guoxunzhong@nuaa.edu.cn, c_cheng@nuaa.edu.cn.
}

\begin{abstract}
The non-uniform distribution of the mechanical properties of welded tube would affect the plastic deformation behavior of tube during the free bending process. To explore the influence of weld position on the forming quality and axis dimensional accuracy of welded tube, the free bending experiment and numerical simulation of welded tube were conducted in this paper. First, the principle of free bending was theoretical deduced and the stress distribution of bent tube was analyzed. Then the hardness test and uniaxial tensile test were conducted to obtain the mechanical properties of weld zone and parent zone of welded tube. The material strength in the weld zone of welded tube is significantly higher than that in the parent zone. Finally, the free bending experiment and numerical simulation with different weld position were carried out, and the influence of weld position on the bending radius, cross-sectional distortion and wall thickness of bent tube was discussed. All these findings advance the insight into the free bending deformation behavior of welded tube and help to improve the forming quality of welded tube and facilitate the application of free bending technology in welded tube.
\end{abstract}

Keywords: Welded tube; Free bending; Non-uniform mechanical properties; Forming quality; Numerical simulation. 


\section{Introduction}

Metallic tube component is widely used in various industrial fields such as aviation, aerospace, nuclear energy engineering and automobile due to its lightweight, high-strength and low energy consumption[1]. The welded tube, as a typical metallic tube component, is becoming more widespread in multitudinous industries owing to the low cost, short production period and great variety[2]. At present, a straight piece of welded tube needs to be formed to a selected radius and angle of bend according to the practical requirements. The traditional bending technologies, such as rotary-draw bending[3], tension-bending[4] and roll bending[5], were mainly used to bend the welded tube. However, with the developing trend of product customization, the demand for the bent tube component with small batch and complex configuration is increasing, as indicated by Yang et al.[6]. It is difficult for the above-mentioned traditional bending technologies to realize the integral forming of welded tube with complex spatial shape. The free bending technology can realize the one-step forming of complex bent tube without changing the bending die, as discussed by Gantner et al.[7]. And this technology shows great potential in the field of welded bent tube manufacturing.

In recent years, numerous researches on the free bending of aluminum alloy and stainless steel tube were carried out. Wu et al.[8] proposed a new theoretical model to describe the springback behavior of pure aluminum spatial tube with different loading modes and hardening materials during free bending process, and found that radii and angles of bent tube both increase accordingly with the increasing of loading index $\boldsymbol{k}$. Beulich et al.[9] developed a simplified simulation model for the free-bending of aluminum alloy tube with a mandrel located inside the tube. And the model was verified by surface measurements of a two-dimensional bending test. Zhou et al.[10] investigated the flexible-bending forming precision of 304 stainless steel tubes and concluded that the springback and residual stress of stainless tubes could be optimized by adjusting the offset of the bending die and the distance between the guide and the die. Zhang et al.[11] studied the springback behavior of pure aluminum tube in bending-twisting deformation process, and concluded that the forming of spatial tubes can be influenced not only by the springback behaviors but also by the initial loading models. To accurately predict the geometry size of the complex bending tubular components during free bending process, Guo et al.[12] proposed a new method to establish the relationship between the deflection of bending die $(U)$ and bending radius $(R)$ of the aluminum alloy circular tube by conducting the sensitivity analysis of material parameters. In addition, Wei et al.[13] found that the wall thickness factor and yield strength are the key material 
parameters that affect the forming limit of metal tubes by conducting the free bending experiment and simulation on the 6061-T6 aluminum alloy tubes. Currently, most researches on the free bending forming technology are based on the seamless tubes, but few scholars have studied the free bending deformation behavior of welded tube.

During the free bending process, the plastic deformation zone of tube is in a less constrained state. The small changes in material parameters will have a significant impact on the forming quality and geometric dimension of the bent tube. Due to the obvious difference in mechanical properties between the weld zone and parent zone of welded tube, the plastic deformation behavior of welded tube is more complicated during the free bending process. At present, the research on the bending deformation behavior of welded tube is mainly based on the traditional bending process. Ren et al.[14] investigated the constraining effects of the weld and heat-affected zone (HAZ) on the tube bend formability of the QSTE340 welded tube by the NC rotary draw bending (RDB) tests and finite element simulation. The results shown that the weld and HAZ materials have obvious constraining effects on the strain distributions in weld and HAZ when the weld line locates on the outside and inside of the bent tube. In addition, the effect of the weld on the strain distribution of the tube during NC bending process was also performed by Ren et al.[15]. The research found that the thickness strain decreases obviously in the weld region when the weld line locates on the outside and inside. Liu et al.[16] established the FE model of RDB of QSTE700 rectangular welded tube considering weld zone and corner and concluded that the weld zone increases the wrinkling height of inner flange and side wall. Zhan et al.[17] proposed an analytical springback model that takes into account the continuous variations of the weld material properties, the anisotropic parameter and the effect of the weld position. The springback angle after bending of the QSTE340 welded tube could be accurately predicted by the above-mentioned model.

Since the material properties of seamless tube are evenly distributed along the cross section, theoretical and experimental studies on the free bending of seamless tubes are quite a few. However, the influence of the difference distribution of material properties of welded tube on the free bending deformation behavior is complicated, the related research on welded tube is considerably little. To accurately characterize the mechanical properties of weld zone and parent zone of welded tube, it is necessary to establish an accurate and continuous constitutive model across the cross section of welded tube. Khalfallah[18] proposed an efficient method to obtain plastic behavior of welded tubes and the constitutive model parameters of weld bead and HAZ regions were determined by tensile tests, rule of mixture and microhard- 
ness test. Likewise, Xing et al.[19] developed a new method for establishing a continuous constitutive model of welded metals via the relationship among the flow stress, microhardness and weld shape. The continuous variation in flow stress across these zones can be characterized by the method. To accurately simulate the deformation behavior of welded steel tube during hydroforming process, the welded tube was modeled as two material system, via: weld zone and base metal region, whose stress-strain curves could be derived by considering the rule of mixture, as presented by Omar et al.[20]. To predict the fracture of welded tube, Jang et al.[21] established the constitutive model of the weld zone by the rule of mixture and the flow stress of the weld was estimated from the hardness ratio. Additionally, Liu et al.[22] analyzed the cross section deformation of thin-walled heterogeneous rectangular welded tube in rotary draw bending by considering different yield criteria. And the anisotropic parameters of Hill' 48 and Barlat' 89 yield criteria of parent zone and weld zone were determined by using the digital image correlation test.

Since the material strength in the weld zone of welded tube is different from that in the parent zone, it is necessary to consider the influence of the non-uniform distribution of material properties on the free bending deformation behavior of welded tube. For this purpose, the free bending mechanism of welded tube was re-derived and the mechanical constitutive relationships of Q345 welded tube was determined by the hardness test, uniaxial tensile test and mixed criterion method. The free bending experiments of welded tube were carried out and the corresponding numerical simulation method was developed. The influence of weld position on $U-R$ relationship, cross-section distortion and wall thickness distribution was studied in detail. Finally, to improve the forming quality and axis dimensional precision of welded tube in the free bending process, the weld position needs to be carefully considered.

\section{Mechanical analysis of welded tube in free bending}

\subsection{Principle of free bending of welded tube}

As a new flexible forming technology, the three-dimensional free bending technology shows great potential in many industrial fields. The process of free bending of tube was illustrated in Fig. 1. The forming equipment is mainly composed of four parts: bearing, bending die, guider and feeding device. The outer spherical surface of bending die is matched with the inner spherical surface of the bearing, and the tail of bending die relates to the head of guider by the special mechanism. Before bending the tube, the center line of the bending die, bearing and guider is on the same axis, which coincides with the feed axis of the equipment. During 
the free bending process, the bending die is in a follow-up state and the tube is always in dynamic contact with the bending die. On the one hand, the center of bending die will move synchronously with the movement of bearing in the X-Y plane. On the other hand, the bending die will rotate around the center of guider when the bending die deviates from the central axis. Therefore, the spatial pose of bending die is determined by the combined motion of the movement in the X-Y plane and the rotation around the guider. In addition, the position of weld can be arbitrarily arranged along the circumferential direction of cross section of bending die in the free bending process of welded tube.

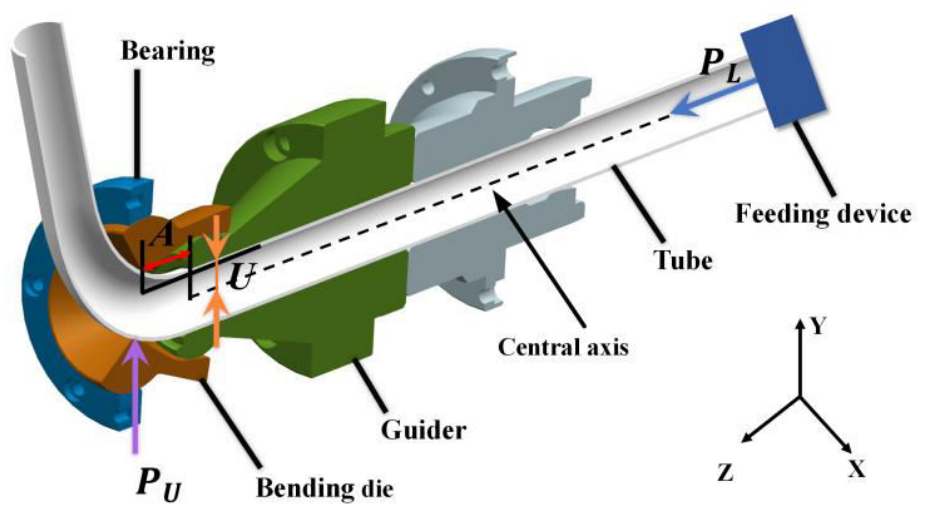

Fig. 1 Schematic diagram of three-dimensional free bending

In the free bending process, the projection distance between the center of bending die and the central axis in the X-Y plane is called as the deflection $\boldsymbol{U}$. Likewise, the distance between the center of bending die and the exit of guider along the central axis is called as the offset $\boldsymbol{A}$. The values of $\boldsymbol{A}$ and $\boldsymbol{U}$ together determine the bending moment exerted by the bending die on the tube. Specifically, the tube is subjected to the axial force $\boldsymbol{P}_{\boldsymbol{L}}$ along the Z-axis exerted by the feed device and the radial force $\boldsymbol{P}_{\boldsymbol{U}}$ perpendicular to the tube axis from the bending die during the free bending process. The combined action of $\boldsymbol{P}_{\boldsymbol{L}}$ and $\boldsymbol{P}_{\boldsymbol{U}}$ forms the bending moment $\boldsymbol{M}$, shown in Eq. (1), which causes the corresponding bending deformation of the welded tube.

$$
M=P_{L} \times U+P_{U} \times A
$$

\subsection{Mechanical analysis of stress-strain}

\section{(1) Fundamental assumption}

Due to the uneven distribution of the material properties of the welded tube along the circumferential direction, its deformation behavior is very complex during free bending process. To analyze the influence of welding line on the plastic deformation behavior of welded tube, 
some assumptions have been made to simplify the derivation process of stress-strain equations.

1) The materials in the weld zone and the parent metal zone satisfy the stress-strain relationship, as shown in Eq. (2):

$$
\sigma=\left\{\begin{array}{l}
E \varepsilon \quad \text { where } \varepsilon \leq \varepsilon_{s} \\
\sigma_{s}+k \times\left(1-e^{-m \varepsilon}\right) \quad \text { where } \varepsilon \geq \varepsilon_{s}
\end{array}\right.
$$

where $E$ is Young's modulus, $m$ is hardening exponent, $k$ is a constant, $\sigma$ is the flow stress, $\varepsilon$ is strain, $\sigma_{s}$ is the yield stress, $\varepsilon_{s}$ is the initial plastic strain.

2) The flow of material along the circumferential direction is ignored during free bending process of welded tube, which can be expressed as:

$$
\varepsilon_{\varphi}=0
$$

3) The shear stress, shear strain and thickness stress are ignored, which are written as:

$$
\begin{cases}\sigma_{i j}=0 & (i \neq j) \\ \varepsilon_{i j}=0 & (i \neq j)\end{cases}
$$

4) The tube is incompressible during free bending process, thus the following relationship can be obtained:

$$
\varepsilon_{\rho}+\varepsilon_{\theta}+\varepsilon_{\varphi}=0
$$

5) The friction between the bending die and welded tube is neglected.

\section{(2) Analysis of stress-strain}

During the free bending process of welded tube, the geometry parameters of tube between the bending die and guider were described in Fig. 2. And the meaning of every symbol was listed in Table 1. The tangential stress-strain $\left(\sigma_{\theta}-\varepsilon_{\theta}\right)$, radial stress-strain $\left(\sigma_{\rho}-\varepsilon_{\rho}\right)$ and circumferential stress-strain $\left(\sigma_{\varphi}-\varepsilon_{\varphi}\right)$ are the principal stress-strain of bent tube. In addition, it is assumed that the welded tube is in the plane strain state and the relationship between principal stresses can be deduced as Eq. (6) by the theory of plastic flow.

$$
\sigma_{\varphi}=\frac{\sigma_{\theta}+\sigma_{\rho}}{2}
$$


Table 1 Definition of every symbol

\begin{tabular}{cl}
\hline Symbols & \\
\hline$R_{\xi}$ & The curvature radius of the strain neutral layer of the bent tube \\
$R_{0}$ & The curvature radius of the original center layer of the bent tube \\
$R_{i}, R_{o}$ & The curvature radius of the intrados and extrados of the bent tube \\
$\xi$ & The transverse displacement distance of strain neutral layer in bent tube \\
$\beta$ & The displacement angle of strain neutral layer in bent tube \\
$\rho$ & The curvature radius at any point of the bent tube \\
$y$ & The distance between any position and the strain neutral layer \\
$d \theta$ & The incremental angle along the tangential direction of bent tube \\
$\varphi$ & The diameter and radius of cross section of the bent tube \\
& The angle between any radius line of tube cross section and original cen- \\
\hline
\end{tabular}
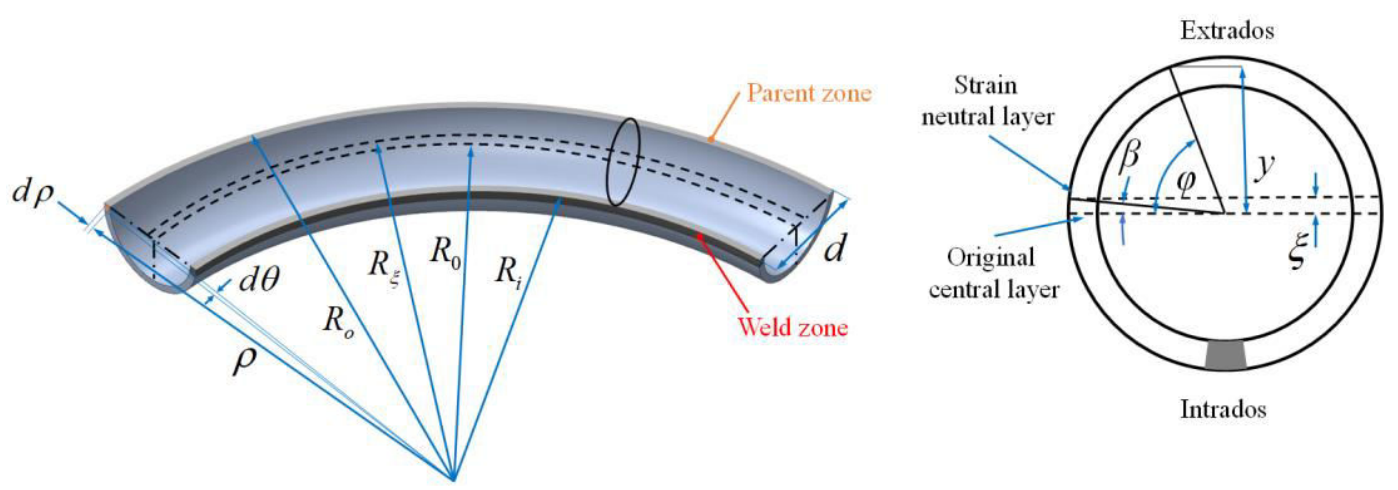

Fig. 2 Geometry parameters of welded tube during free bending process

According to Hency stress-strain relationship and Eq. (6), the stress balance equation can be expressed as Eq. (7) in the radial direction.

$$
\frac{d \sigma_{\rho}}{d \rho}+\frac{\sigma_{\rho}-\sigma_{\theta}}{\rho}=0
$$

Based on the von Mises yield criterion, the equivalent stress and strain of the welded tube during free bending process can be deduced as Eqs. (8) and (9).

$$
\bar{\sigma}=\frac{\sqrt{3}}{2}\left|\sigma_{\theta}-\sigma_{\rho}\right|
$$




$$
\bar{\varepsilon}=\sqrt{\frac{2}{3}\left(\varepsilon_{\rho}^{2}+\varepsilon_{\theta}^{2}+\varepsilon_{\varphi}^{2}\right)}=\frac{2}{\sqrt{3}}\left|\varepsilon_{\theta}\right|
$$

Due to the additional axial force $\boldsymbol{P}_{\boldsymbol{L}}$ exerted on the tube, the strain-neutral layer is shifted from the inside to the outside of the tube. Thus, the tangential strain of the welded tube can be expressed as:

$$
\varepsilon_{\theta}=\frac{\left(R_{\xi}+y\right) d \theta-R_{\xi} d \theta}{R_{\xi} d \theta}=\frac{r \sin \varphi-r \sin \beta}{R_{0}+r \sin \beta}
$$

By substituting Eqs. (8), (9) and (10) into (2), the following equation was obtained:

$$
\left|\sigma_{\theta}-\sigma_{\rho}\right|=\frac{2}{\sqrt{3}}\left\{\sigma_{s}+k\left(1-e^{-\frac{2}{\sqrt{3}} m\left|\frac{r \sin \varphi-r \sin \beta}{R_{0}+r \sin \beta}\right|}\right)\right\}
$$

when $\varphi \in[\beta, \pi-\beta], r \sin \varphi-r \sin \beta>0 ; \varphi \in[\pi-\beta, \beta], r \sin \varphi-r \sin \beta<0$.

According to Eqs. (7) and (11), the radial stress $\sigma_{\rho i}$ and $\sigma_{\rho o}$ inside and outside of bent tube were constructed as:

$$
\begin{aligned}
& \sigma_{\rho i}=\left\{-\frac{2}{\sqrt{3}}\left[\sigma_{s}+k\left(1-e^{\frac{2}{\sqrt{3}} m \frac{r \sin \varphi-r \sin \beta}{R_{0}+r \sin \beta}}\right)\right]\right\} \ln \rho+C_{i} \\
& \sigma_{\rho o}=\left\{\frac{2}{\sqrt{3}}\left[\sigma_{s}+k\left(1-e^{-\frac{2}{\sqrt{3}} m \frac{r \sin \varphi-r \sin \beta}{R_{0}+r \sin \beta}}\right)\right]\right\} \ln \rho+C_{o}
\end{aligned}
$$

where $C_{i}, C_{o}$ are the integration constant. Since the radial stress $\sigma_{\rho}$ is equal to zero in the innermost and outermost of bent tube surface, the radial stress inside and outside of bent tube can be deduced as Eqs. (14) and (15) respectively:

$$
\begin{gathered}
\sigma_{\rho i}=\frac{2}{\sqrt{3}}\left[\left(\sigma_{s}+k\right) \ln \frac{R_{i}}{\rho}+k e^{\frac{2}{\sqrt{3}} m\left(\frac{r \sin \varphi-r \sin \beta}{R_{0}+r \sin \beta}\right)} \ln \rho-k e^{\left.\frac{2}{\sqrt{3} m\left(\frac{r-r \sin \beta}{R_{0}+r \sin \beta}\right)} \ln R_{i}\right]}\right. \\
\sigma_{\rho o}=\frac{2}{\sqrt{3}}\left[\left(\sigma_{s}+k\right) \ln \frac{\rho}{R_{o}}+k e^{-\frac{2}{\sqrt{3}} m\left(\frac{r+r \sin \beta}{R_{0}+r \sin \beta}\right)} \ln R_{o}-k e^{-\frac{2}{\sqrt{3}} m\left(\frac{r \sin \varphi-r \sin \beta}{R_{0}+r \sin \beta}\right)} \ln \rho\right]
\end{gathered}
$$

According to Eqs. (11), (14) and (15), the tangential stress inside and outside of the bent tube can be written as Eqs (16) and (17) respectively:

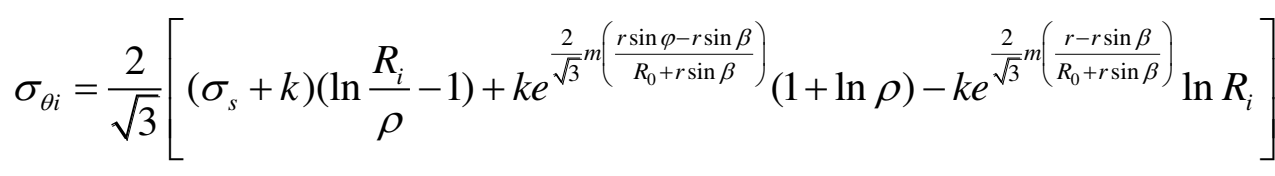




$$
\sigma_{\theta o}=\frac{2}{\sqrt{3}}\left[\left(\sigma_{s}+k\right)\left(\ln \frac{\rho}{R_{o}}+1\right)-k e^{-\frac{2}{\sqrt{3}} m\left(\frac{r \sin \varphi-r \sin \beta}{R_{0}+r \sin \beta}\right)}(1+\ln \rho)+k e^{-\frac{2}{\sqrt{3}} m\left(\frac{r+r \sin \beta}{R_{0}+r \sin \beta}\right)} \ln R_{o}\right]
$$

Combining Eqs. (6), (16) and (17), the circumferential stress inside and outside of the bent tube can be derived as (18) and (19) respectively:

$$
\begin{gathered}
\sigma_{\varphi i}=\frac{2}{\sqrt{3}}\left[\left(\sigma_{s}+k\right)\left(\ln \frac{R_{i}}{\rho}-\frac{1}{2}\right)+k e^{\frac{2}{\sqrt{3}} m\left(\frac{r \sin \varphi-r \sin \beta}{R_{0}+r \sin \beta}\right)}\left(\frac{1}{2}+\ln \rho\right)-k e^{\frac{2}{\sqrt{3}} m\left(\frac{r-r \sin \beta}{R_{0}+r \sin \beta}\right)} \ln R_{i}\right] \\
\sigma_{\varphi o}=\frac{2}{\sqrt{3}}\left[\left(\sigma_{s}+k\right)\left(\ln \frac{\rho}{R_{o}}+\frac{1}{2}\right)-k e^{-\frac{2}{\sqrt{3}} m\left(\frac{r \sin \varphi-r \sin \beta}{R_{0}+r \sin \beta}\right)}\left(\frac{1}{2}+\ln \rho\right)+k e^{-\frac{2}{\sqrt{3}} m\left(\frac{r+r \sin \beta}{R_{0}+r \sin \beta}\right)} \ln R_{o}\right]
\end{gathered}
$$

\subsection{Analysis on the shift of strain neutral layer}

In the free bending process, the additional axial force $\boldsymbol{P}_{\boldsymbol{L}}$ is uniformly and independently acted on the bent tube along the tangential direction. To maintain the shape of bent tube, the tangential stress generated by the axial force $\boldsymbol{P}_{\boldsymbol{L}}$ and bending moment must satisfy the condition of stress equilibrium. Hence, the following equation can be expressed as:

$$
\int_{\pi+\beta}^{2 \pi-\beta}\left[\sigma_{s}+k\left(1-e^{-m \frac{r \sin \varphi-r \sin \beta}{R_{o}-r \sin \beta}}\right)\right] r_{m} t_{o} d \varphi+\int_{-\beta}^{\pi+\beta}\left[-\sigma_{s}+k\left(1-e^{-m \frac{r \sin \varphi-r \sin \beta}{R_{o}-r \sin \beta}}\right)\right] r_{m} t_{i} d \varphi=0
$$

During traditional tube bending (pure bending), in order to ensure the balance between stress-strain and deformation area, the strain neutral layer keeps moving towards the center of the bending direction under the action of bending moment. However, in the process of free bending, the tangential tensile stress in the outside of the bending direction decreases due to the action of additional axial force $\boldsymbol{P}_{\boldsymbol{L}}$. In that way, the trend of strain neutral layer towards the center of bend decreases. When the additional axial force $\boldsymbol{P}_{\boldsymbol{L}}$ is large enough, the strain neutral layer will start to move outward in the bending direction, which is shown in the Eq (20).

\section{Free bending experiment and simulation of welded tube}

\subsection{Hardness experiment}

In this paper, the Q345 welded tube with the diameter of $31.6 \mathrm{~mm}$ and the wall thickness of $2 \mathrm{~mm}$ was used to study the influence of weld on free bending deformation behavior. Since the mechanical property of tube in the weld zone is different from that in the parent zone of 
tube, it is necessary to first determine the distribution area of weld along the circumferential direction in the welded tube. For simplification, the heat-affected zone (HAZ) and welded joint are considered as the weld zone in the welded tube. Here the hardness experiment was employed to distinguish the weld zone from the parent zone. The cross-section specimen of welded tube was prepared for the hardness experiment. As shown in Fig. 3, the test points for hardness experiment were evenly distributed along the circumferential direction of tube with the interval of $0.5 \mathrm{~mm}$, which covers the weld zone and parent zone. To avoid the accidental deviation in the measurement process, the hardness experiments were conducted three times. And the microhardness distribution across the weld zone and parent zone of Q345 welded tube was shown in Fig. 4. It could be found that the microhardness value of weld zone is significantly higher than that of parent zone and the microhardness value at the center line of the welded zone is the largest. According to the evolution trend of the microhardness distribution in the weld zone and parent zone of welded tube, the width of weld zone can be determined to be $4 \mathrm{~mm}$, as shown by the fitting curve in Fig. 4.

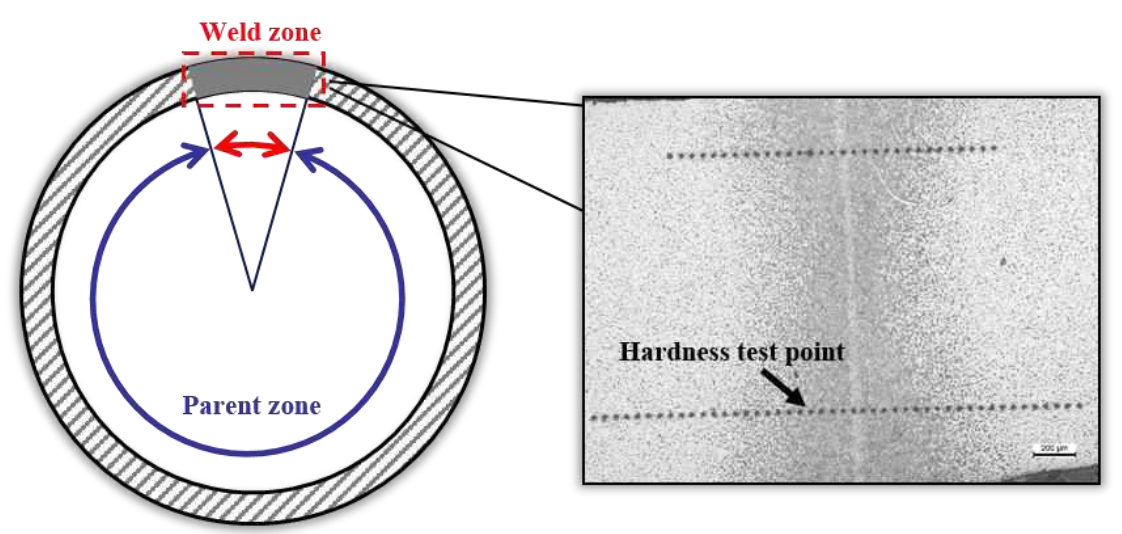

Fig. 3 Hardness experiment of the welded tube

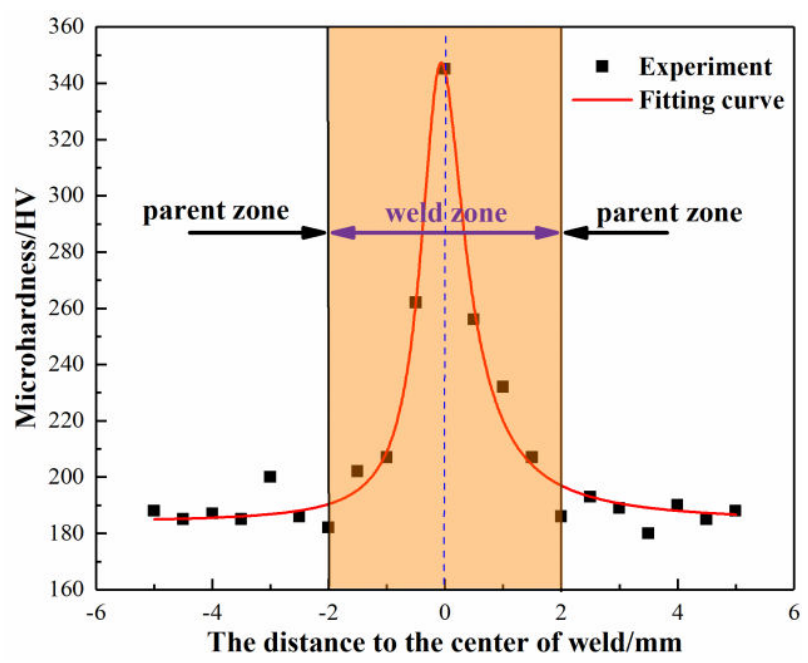

Fig. 4 Microhardness distribution in the weld zone and parent zone 


\subsection{Uniaxial tensile test}

To accurately determine the mechanical property parameters of weld zone and parent zone in the welded tube, the uniaxial tensile tests for the materials in different zones of welded tube were carried out. The uniaxial tensile specimens in the parent zone were prepared along the axial direction, as shown in the Fig. 5(a). Due to the narrow weld zone, the uniaxial tensile specimens in the mixed zone containing the weld zone and parent zone were prepared to avoid the impact of cutting on the mechanical properties of the weld, as shown in the Fig. 5(a). The geometrical dimension of uniaxial tensile specimen was also illustrated in Fig. 5(b).

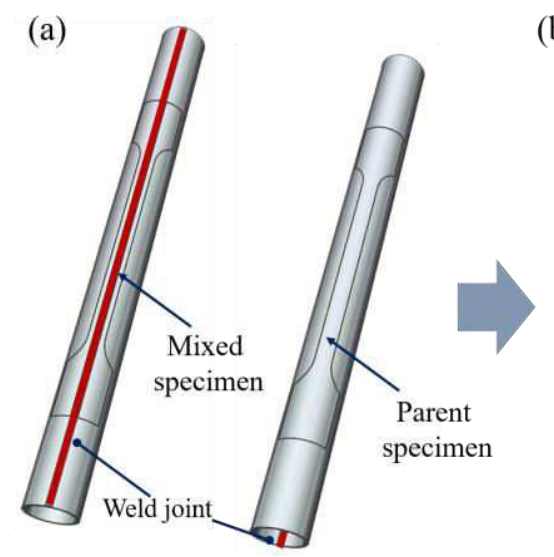

(b)

Fig. 5 Uniaxial tensile specimens: (a) specimen taken along the axial direction; (b) geometrical dimension

The flow stress-strain curves of parent zone and mixed zone (parent zone + weld zone) were displayed in Fig. 6. As we can found, the yield stress of the mixed zone is significantly higher than that in the parent zone, which is consistent with the evolution of hardness distribution in Fig. 4. The Eq. (2) was employed to fit the stress-strain curve of parent zone, and the fitting results were shown in Fig. 6 and Table 2.

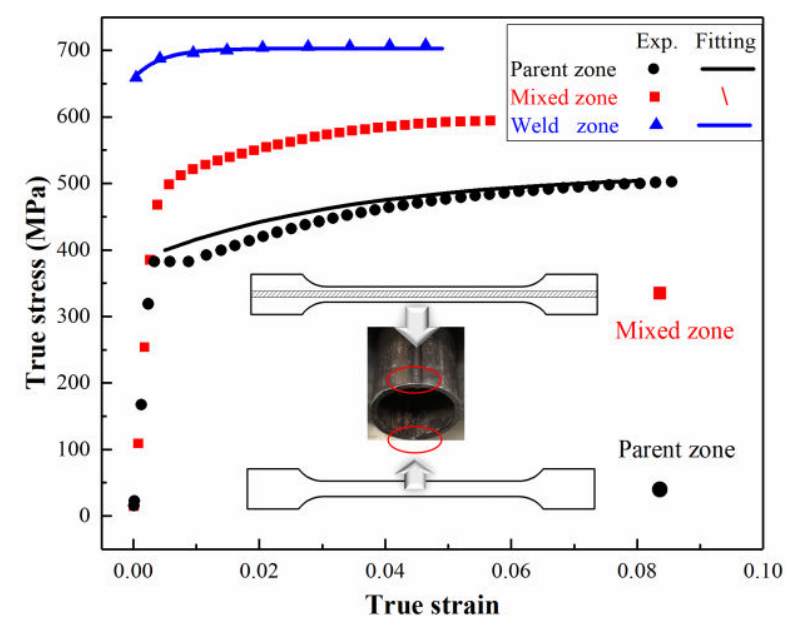

Fig. 6 The flow stress-strain curves of welded tube 
Table 2 Mechanical property parameters in different zones

\begin{tabular}{ccccc}
\hline Zone & $\sigma_{s}(\mathrm{MPa})$ & $k$ & $m$ & $C O D\left(R^{2}\right)$ \\
\hline Parent zone & 381.41 & 135.16 & 29.56 & 0.99985 \\
Mixed zone & 501.42 & 103.87 & 46.39 & 0.99874 \\
Weld zone & 657.88 & 44.86 & 229.30 & 0.98525 \\
\hline
\end{tabular}

To obtain the constitutive model of weld zone, it is necessary to separate the parent zone from the mixed zone, whose principle is shown in Fig. 7. The mixed uniaxial tensile specimen is composed of two parts: parent zone and weld zone. It is assumed that the strain along the tensile direction of parent zone and weld zone are the same during the uniaxial tensile test, which can be expressed as Eq. (21).

$$
\varepsilon_{m}=\varepsilon_{p}=\varepsilon_{w}
$$

where $\varepsilon_{m}$ is the total strain of the mixed uniaxial tensile specimen, $\varepsilon_{p}$ is the strain of parent zone and $\varepsilon_{w}$ is the strain of weld zone.

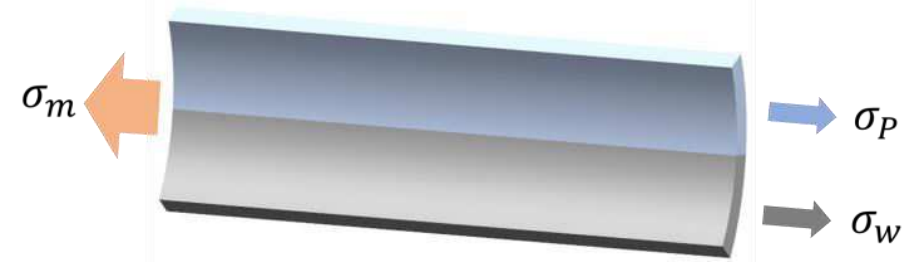

Fig. 7 Stress distribution of mixed uniaxial tensile specimen

According to the condition of stress equilibrium, the stress relationship between weld zone and parent zone can be derived as Eq. (22).

$$
\sigma_{w}=\frac{\sigma_{m} \cdot L_{m}-\sigma_{p} \cdot L_{p}}{L_{w}}
$$

where $\sigma_{m}$ and $L_{m}$ are the stress and width of the mixed zone, $\sigma_{p}$ and $L_{p}$ are the stress and width of the parent zone, $\sigma_{w}$ and $L_{w}$ are the stress and width of the weld zone. Therefore, the flow stress-strain curve of the weld zone can be derived from the Eq. (22) and Fig. 6, which was also shown in Fig. 6. In addition, the Eq. (2) was used to fit the stress-strain curve of weld zone, and the fitting results were shown in Fig. 6 and Table 2. It was found that the material strength in the weld zone is significantly higher than that in the parent zone and the Eq. (2) could accurately describe the flow behavior of parent zone and weld zone of Q345 welded tube. 


\subsection{Free bending experiment}

The free bending experiment of Q345 welded tube was conducted on the three-axial free bending forming equipment developed by $N U A A$, as shown in the Fig. 8. The inner diameter of bending die is $32 \mathrm{~mm}$ in the free bending system. During the free bending process, the welded tube passes through the guider and bending die in turn under the action of feeding device. Since the spatial position and posture of the bending die can be adjusted continuously, the bending radius and angle of bent tube also change accordingly. Finally, the welded tube is bent into the pre-designed shape under the combined action of the bending die, guider and feeding device.
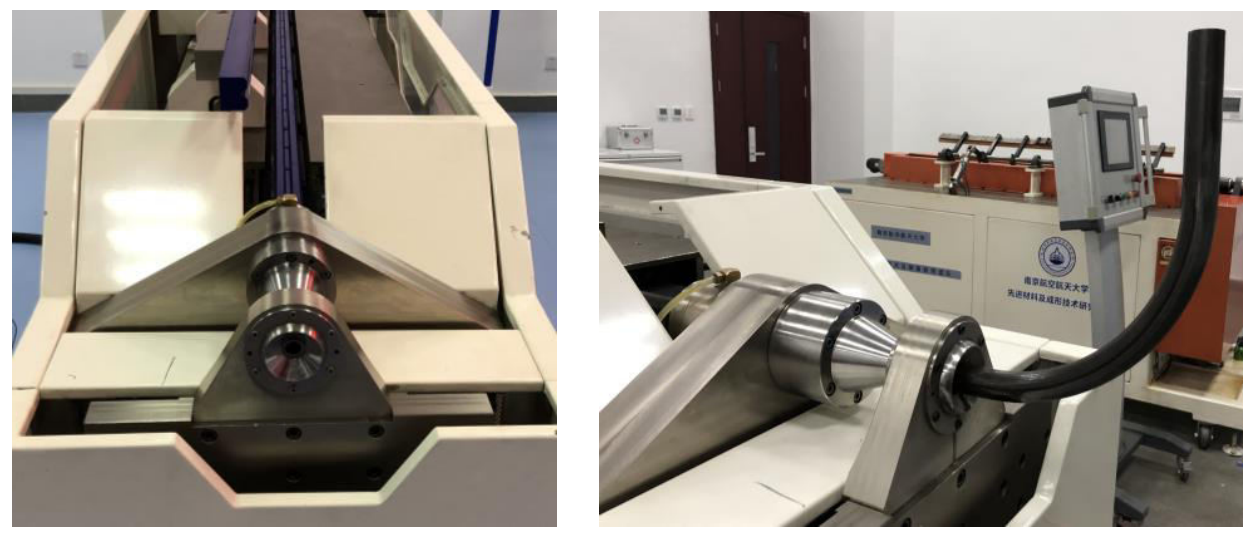

Fig. 8 Three-axial free bending forming equipment

Considering that the material mechanical properties of welded tube are unevenly distributed along the circumferential direction of cross section and the materials in different zones are in different stress states, it is necessary to study the influence of weld position on the free bending deformation behavior of welded tube. In this paper, the free bending experiments of welded tube with different weld positions were carried out and the welds were arranged on the outside, inside and right-side of bent tube, as shown in Fig. 9. And the evolution of the bending radius, wall thickness and cross-section distortion with the position of weld was explored by free bending experiment and simulation. The feeding speed of tube and movement speed of bending die were set to be $10 \mathrm{~mm} / \mathrm{sec}$ and $2 \mathrm{~mm} / \mathrm{sec}$, respectively. To analyze the evolution of bending radius with the deflection $\boldsymbol{U}$ of bending die, the free bending experiments with the deflection $\boldsymbol{U}$ of $4 \mathrm{~mm}, 6 \mathrm{~mm}, 8 \mathrm{~mm}, 10 \mathrm{~mm}, 12 \mathrm{~mm}, 14 \mathrm{~mm}$ were implemented. In addition, the lubricating oil was also used between welded tube and bending die. 

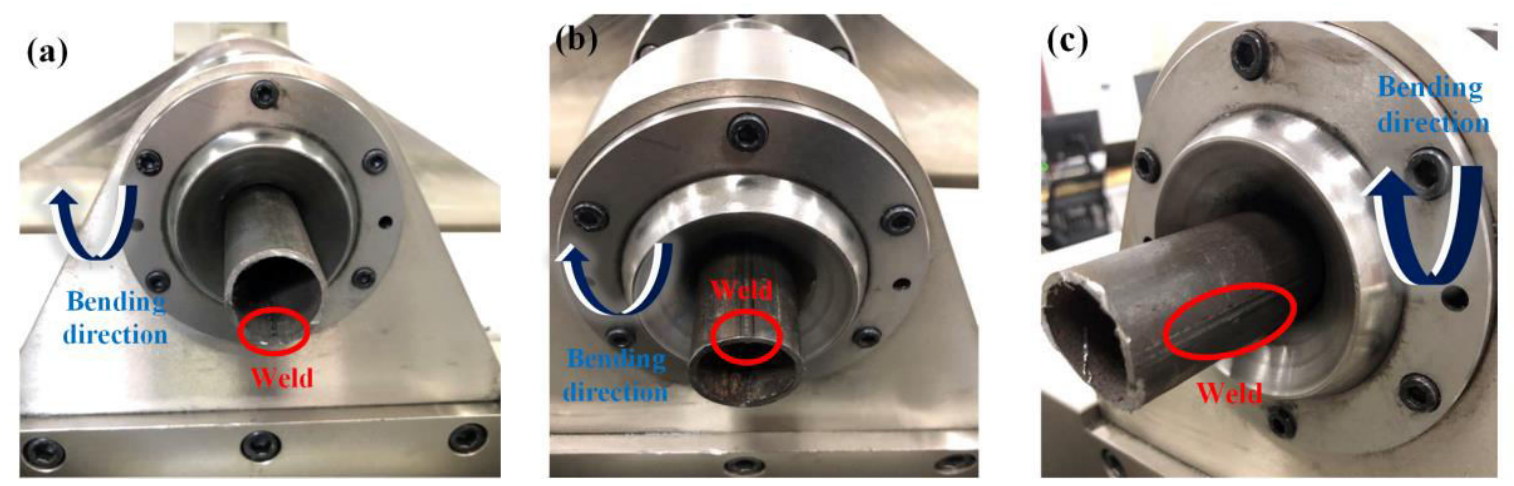

Fig. 9 Free bending experiments of welded tube with different weld position: (a) outside of bent tube; (b) inside of bent tube; (c) right-side of bent tube

\subsection{Finite element simulation}

To investigate the influence of weld on the free bending deformation behavior of welded tube more deeply and conveniently, the finite element method was employed to simulate the forming process. As shown in Fig. 10, the 3D FE model was established in the ABAQUS/Explicit platform, which includes the bending die, bearing, guider and welded tube. Due to the uneven distribution of material properties along the circumferential direction of cross section of welded tube, the weld zone and parent zone should be given different material constitutive models, as listed in Table 2. To balance the simulation accuracy and calculation efficiency, the mesh size of weld zone and parent zone of welded tube were set to be 1.2 $\mathrm{mm}$ and $2.0 \mathrm{~mm}$. And the tube was meshed by 4-node shell elements (S4R). Considering that the bending die, bearing and guider hardly undergo plastic deformation during free bending process, they were dispersed by C3D10M solid elements and defined as rigid bodies. The interaction between different modules was set to be the general contact. Since the lubrication oil was used between bending die and tube, the friction coefficient was set to be 0.02 . Other simulation process parameters setting can refer to the free bending forming experiment. In addition, the free bending deformation behavior of Q345 tube without weld would be also simulated numerically and the mechanical properties of parent zone were assigned to the whole tube. 


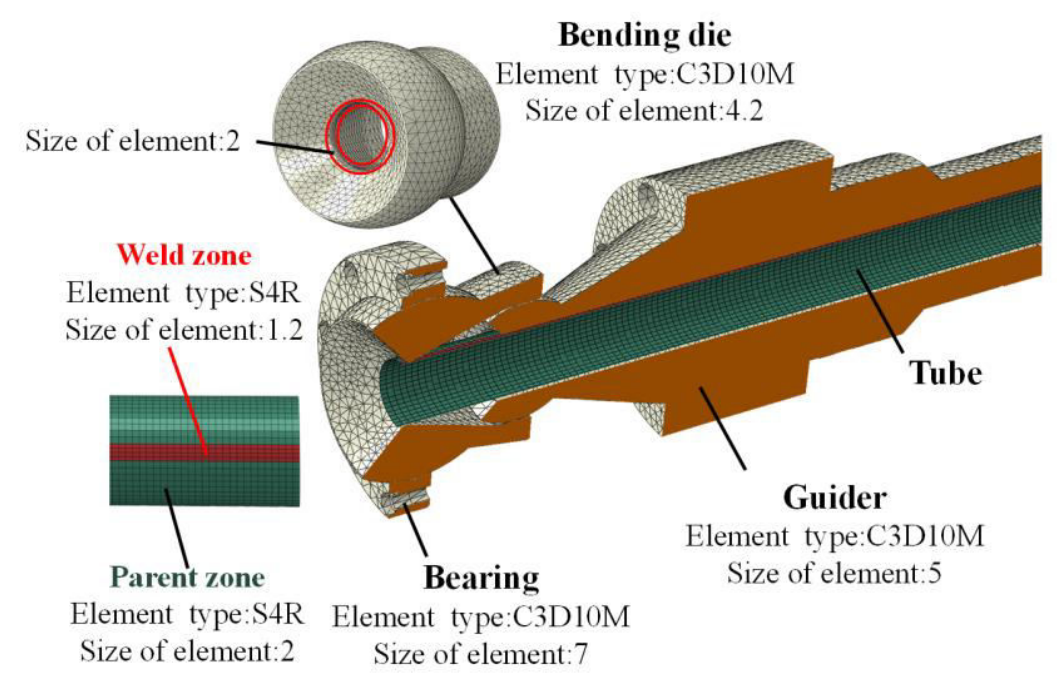

Fig. 10 FE model of free bending of welded tube

\section{Results and discussion}

According to the previous analysis, the mechanical property of weld zone is significant different from that in parent zone. The different areas of tube along cross section are in different stress states during free bending process. The coupling effect between the non-uniform distribution of the material and the stress state of tensile-compression makes the free bending deformation behavior of welded tube more complicated. In this paper, the influence of weld position on the distribution of wall thickness, $U-R$ relationship and cross-sectional distortion would be analyzed by free bending experiments and numerical simulation. In addition, the free bending deformation behavior of non-welded tube was also discussed. Here, four typical positions of weld were divided, which include the outside of the bending direction (WOD), the right-side of the bending direction (WRD), the inside of the bending direction (WID) and tube without weld (Non-weld).

\subsection{Comparison of simulation and experimental results}

To explore the influence of weld on the free bending deformation behavior of tube, the results of free bending of welded tube and non-welded tube need to be compared. Due to the lack of Q235 non-welded tube, the free bending forming process of non-welded tube can be characterized by the finite element numerical simulation method. Therefore, it is necessary to first verify the feasibility of numerical simulation method. The finite element numerical simulation and experiment of free bending of welded tube were conducted and the corresponding bent tubes were shown in Fig. 11(a). The deflection $\boldsymbol{U}$ of bending die was set to be $6 \mathrm{~mm}$ and 
the weld is arranged on the right-side of the bending direction. It was found that the shape of simulated bent tube is similar to that of experimental bent tube and the bending radius obtained by simulation is slightly larger than the experimental result. This may be attributed to the fluctuation in the mechanical properties of welded tube. In addition, the simulation result of free bending of non-welded tube was also compared in Fig. 11(b). The simulated bending radii of welded and non-welded tubes are almost the same. Hence, it could be preliminarily concluded that the free bending forming process of non-welded tube can be accurately described by numerical simulation method.

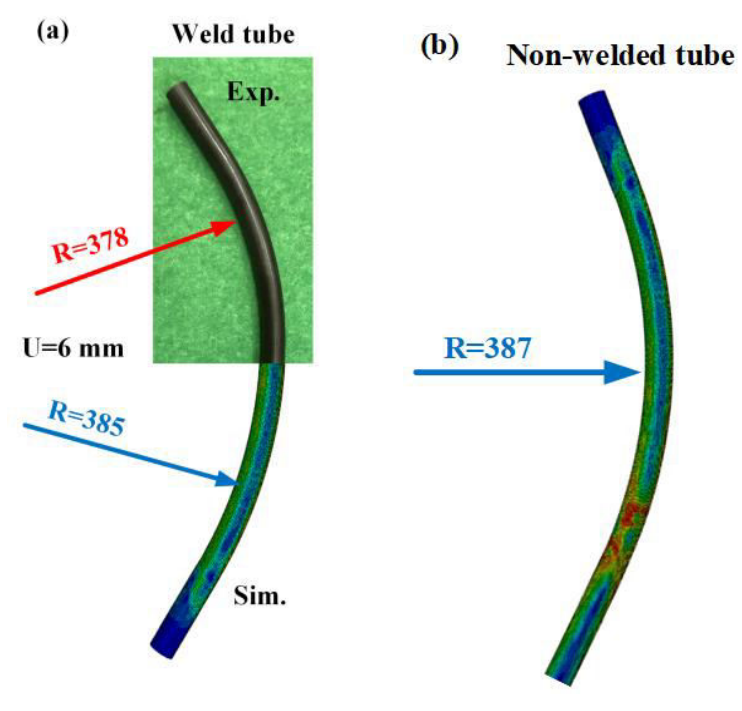

Fig. 11 Comparison of the experimental and simulation bent tubes: (a) experimental and simulation bent tube with weld; (b) simulation bent tube without weld

In addition, the wall thickness distribution of the simulated and experimental bent tubes was shown in Fig. 12. When the weld in located at the right-side of the bending direction, the numerical simulation results of the welded tube and non-welded tube are basically the same, which are relatively close to the experiment results. The increase in the wall thickness of the intrados of bent tube is significantly higher than the reduction in the wall thickness of the extrados of bent tube, which is attributed to the fact that the axial force $\boldsymbol{P}_{\boldsymbol{L}}$ along the Z-axis suppresses the thinning of the outer wall thickness. The above analysis shown that the free bending forming process of welded tube and non-welded tube can be reasonably characterized by numerical simulation method. 


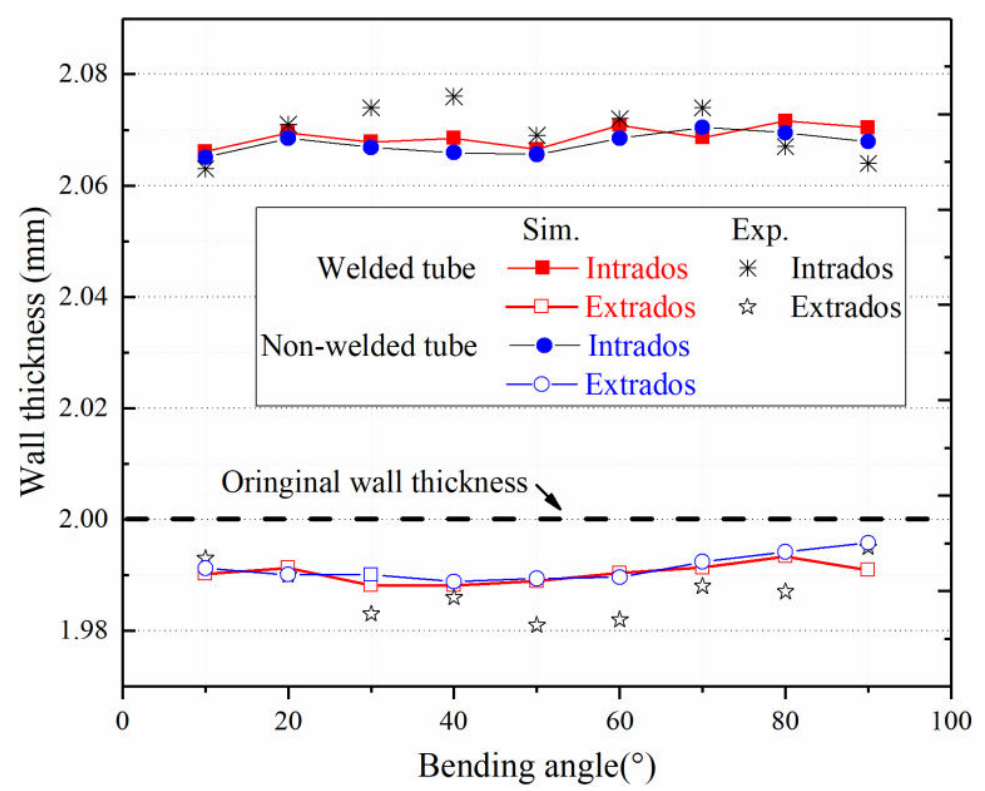

Fig. 12 Wall thickness distribution of welded and non-welded tubes

\subsection{Influence of weld position on $U-R$ relationship}

Due to the inconsistency of mechanical properties between the weld zone and parent zone of welded tube and the different stress states of inside and outside of bent tube during free bending process, the plastic deformation behavior and springback evolution law of welded tube are very complicated, which further affects the axial shape and size of the bent tube. The Fig. 13 (a) shown the experimental bent tubes with different deflection $\boldsymbol{U}$ and weld on the right-side of bending direction. And the relationships between the bending radius of bent tube $\boldsymbol{R}$ and the deflection $\boldsymbol{U}$ of bending die under different weld position conditions were also concluded in Fig. 13 (b). It could be found that the position of weld has a significant influence on the $\boldsymbol{U}-\boldsymbol{R}$ relationship when the deflection $\boldsymbol{U}$ of bending die is relatively small. When the weld of welded tube is located at the inside, outside and right-side of bending direction respectively, the corresponding bending radius decreases in sequence under the condition of the same deflection $\boldsymbol{U}$. And the numerical simulation result of free bending of non-welded tube was also shown in Fig. 13, which is close to the case where the weld is located at the right-side of bending direction. However, the weld position hardly affects the $\boldsymbol{U}-\boldsymbol{R}$ relationship when the deflection $\boldsymbol{U}$ of bending die is large. 

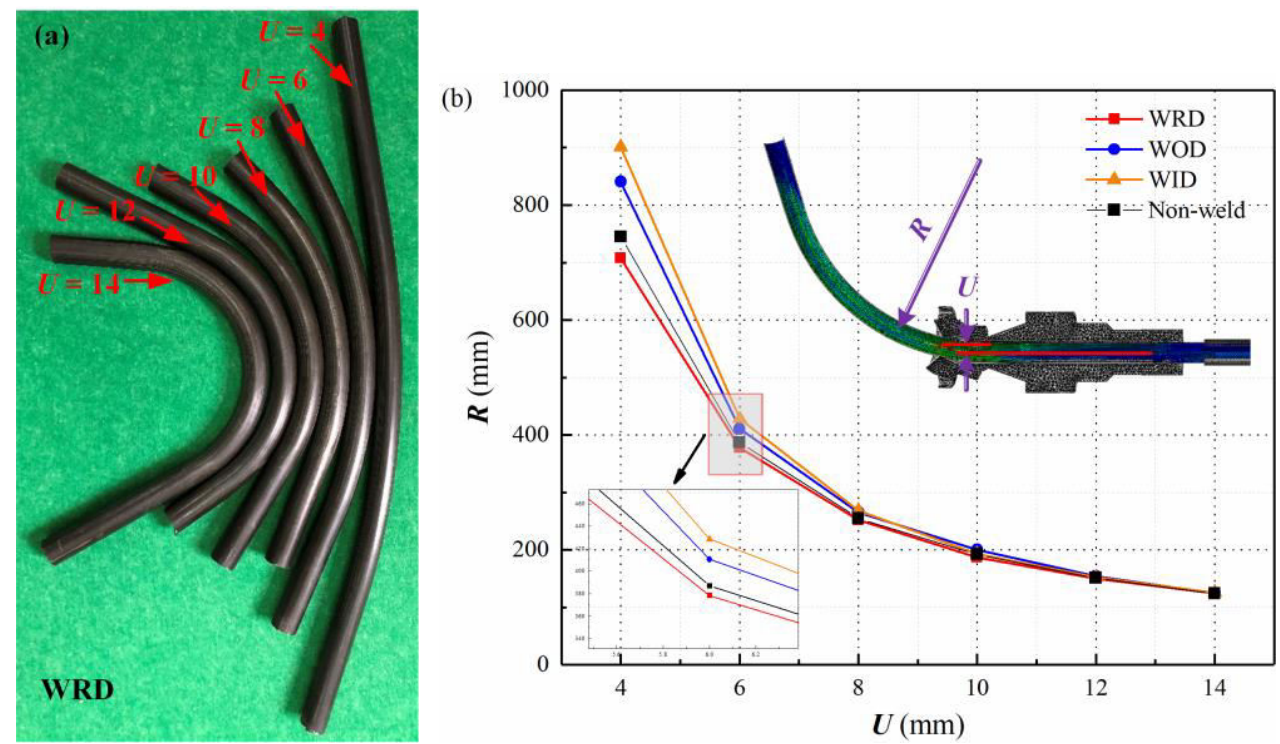

Fig. $13 \boldsymbol{U}$ - $\boldsymbol{R}$ relationship of welded tube and non-welded tube: (a) experimental bent tube; (b)

\section{$\boldsymbol{U}-\boldsymbol{R}$ relationship}

The influence of weld position on $\boldsymbol{U}-\boldsymbol{R}$ relationship of welded tube could be analyzed and explained from the perspective of the springback of bent tube and the distribution of stress-strain. According to the conclusions of previous research, the mechanical properties of material have an impact on the springback behavior of component and the degree of springback increases with the increases of yield strength and strain hardening index. Since the material strength in the weld zone is significantly higher than that in the parent zone, the springback of bent tube with the weld located at the outside or inside of bending direction is significantly larger than that with the weld located at the right-side of bending direction, resulting in the increase of bending radius. Considering that the weld on the right-side of bending direction hardly undergoes plastic deformation during the free bending process, the weld has little effect on the springback behavior of the welded tube and the experimental results are close to the numerical simulation results of the non-welded tube.

In addition, the deformation of the inside of bent tube is greater under the action of axial thrust, resulting in the more obvious springback behavior when the weld is located at the inside of bending direction. With the increase of the deflection $\boldsymbol{U}$ of bending die, the deformation degree of welded tube increases and the proportion of elastic strain in the total strain decreases. Thus the shape and size of the bent tube are less affected by the spingback behavior and the influence of the weld position on the radius of welded tube could be ignored. 


\subsection{Influence of weld position on cross-sectional distortion}

To quantitatively describe the influence of the weld position on the cross-sectional distortion, the cross-sectional distortion rate $\gamma$ was introduced to reflect the flattening degree of tube, as shown in Fig. 14, which was defined as:

$$
\gamma=\frac{d_{\max }-d_{\min }}{d_{0}} \times 100 \%
$$

where $d_{0}$ is the initial diameter of welded tube, $d_{\max }$ and $d_{\min }$ are the maximum and minimum diameters of cross section of bent tube.

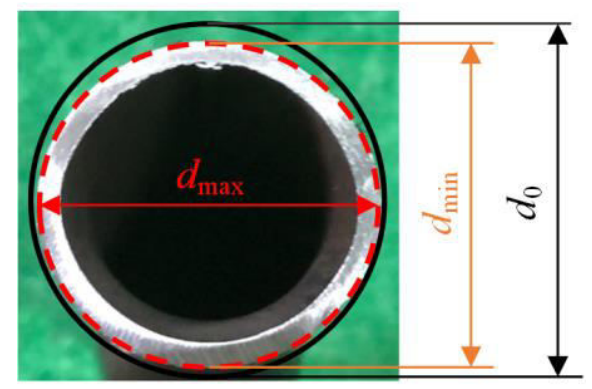

Fig. 14 Schematic diagram of measuring cross-sectional distortion rate

The evolution law of cross-sectional distortion rate $\gamma$ with the deflection $\boldsymbol{U}$ of bending die was obtained by free bending experiments under different weld position conditions, which was shown in Fig. 15. And the cross-sectional distortion rate $\gamma$ of the non-welded tube obtained by the numerical simulation method was also compared in Fig. 15. The cross-sectional distortion rate of the bent tube increases with the increase of the deflection $\boldsymbol{U}$ of bending die, which can be attributed to that the severe plastic deformation of tube under the larger deflection $\boldsymbol{U}$ would further aggravate the flattening degree of bent tube. In addition, when the weld of welded tube is located at the inside, outside and right-side of bending direction respectively, the corresponding cross-sectional distortion rate $\gamma$ decreases in sequence under the condition of the same deflection $\boldsymbol{U}$. Furthermore, the effect of weld position on the cross-sectional distortion rate $\gamma$ might be ignored when the deflection $\boldsymbol{U}$ is small. Compared with the case where the weld is on the outside or inside of bending direction, the cross-sectional distortion rate $\gamma$ of welded tube with right-side weld is almost consistent with the numerical simulation results of non-welded tube. 


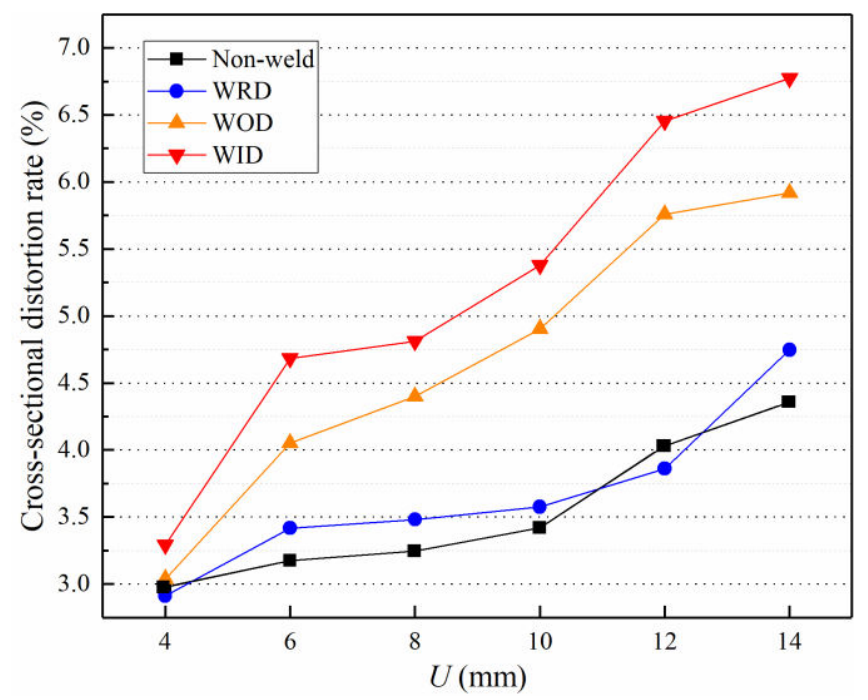

Fig. 15 Cross-sectional distortion rate of the bent tube under different deflection $\boldsymbol{U}$

In the process of free bending, the stress state and cross-sectional deformation of bent tube were shown in Fig. 16. By analyzing the distribution of tangential stress in the process of bending, the tube is bent under the action of bending moment $\boldsymbol{M}$. The resultant force $\left(N_{1}, N_{2}\right)$ of tangential tensile stress $\sigma_{\theta o}$ on the outside of bent tube and tangential compressive stress $\sigma_{\theta i}$ on the inside of bent tube point to the center of cross section of bent tube, causing the flattening deformation of tube along the direction of $N_{1}$ and $N_{2}$. Since the yield stress of material in the weld zone is larger than that in the parent zone, it can be deduced from Eq. (16) and (17) that the tangential compressive stress or tangential tensile stress in the weld zone is greater than that in the parent zone under the same deformation condition. When the weld is located at the outside or inside of bending direction, the deformation resistance of tube is greater and the larger resultant $N_{1}$ or $N_{2}$ would cause more severe cross-sectional distortion. In addition, the cross-sectional distortion rate $\gamma$ of welded tube with inside weld is greater than that with outside weld, which can be attributed to the fact that the tangential compressive stress on the inside of bending direction is larger than the tangential tensile stress on the outside of bending direction under the action of axial force $\boldsymbol{P}_{\boldsymbol{L}}$. When the weld is located at the right-side of bending direction, the weld zone is close to the position of the strain-neutral layer and the plastic deformation of weld zone could be ignored. Thus, the cross-sectional distortion rate $\gamma$ of welded tube with right-side weld is almost consistent with the numerical simulation results of non-welded tube. 


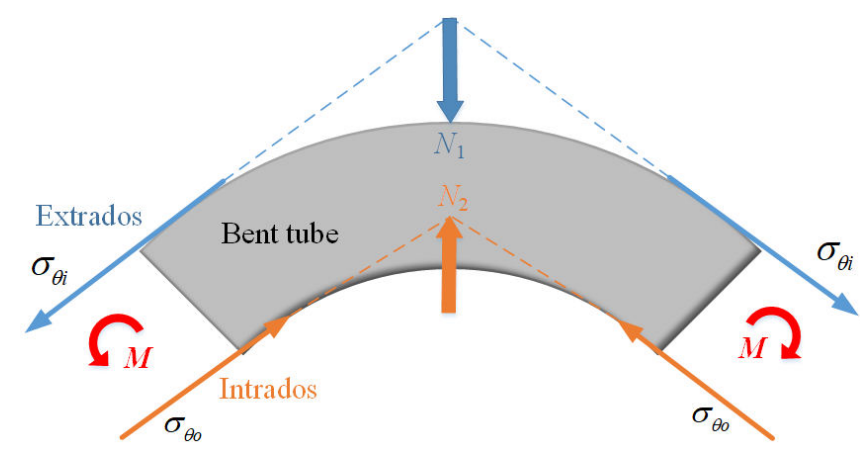

Fig. 16 Cross-sectional deformation of bent tube

\subsection{Influence of weld position on the wall thickness distribution}

The evolution of the inner and outer wall thickness distribution of welded tube with the weld position under different deflection $\boldsymbol{U}$ conditions was obtained by the finite element simulation, which was depicted in Fig. 17. The wall thickness was measured from the stable arc segment of bent tube, and the true distance refers to the length from the starting position of curved arc segment. It was found that the increase in the wall thickness of the intrados of bent tube is significantly higher than the reduction in the wall thickness of the extrados of bent tube. With the increase of deflection $\boldsymbol{U}$, the thinning of the wall thickness of the extrados and the thickening of the wall thickness of the intrados becomes more obvious. In addition, when the weld is located at the outside of the bending direction, the thickening of intrados of welded tube and thinning of extrados of welded tube is becoming more severe. Compared with the results of free bending of welded tube with right-side weld, the thickening of the wall thickness of the intrados and the thinning of the wall thickness of the extrados would be weakened when the weld is located at the inside of bending direction. Moreover, the wall thickness distribution of non-welded tube is basically consistent with the results of free bending of welded tube with right-side weld. Hence, it could be concluded that the influence of weld on the change of wall thickness is very significant when the weld is on the outside of bending direction, resulting in more uneven wall thickness distribution of welded tube. When the weld is located at the inside of bending direction, the thickening of intrados and thinning of extrados of bent tube would be suppressed, and the uniformity of thickness distribution of welded tube could be improved. 

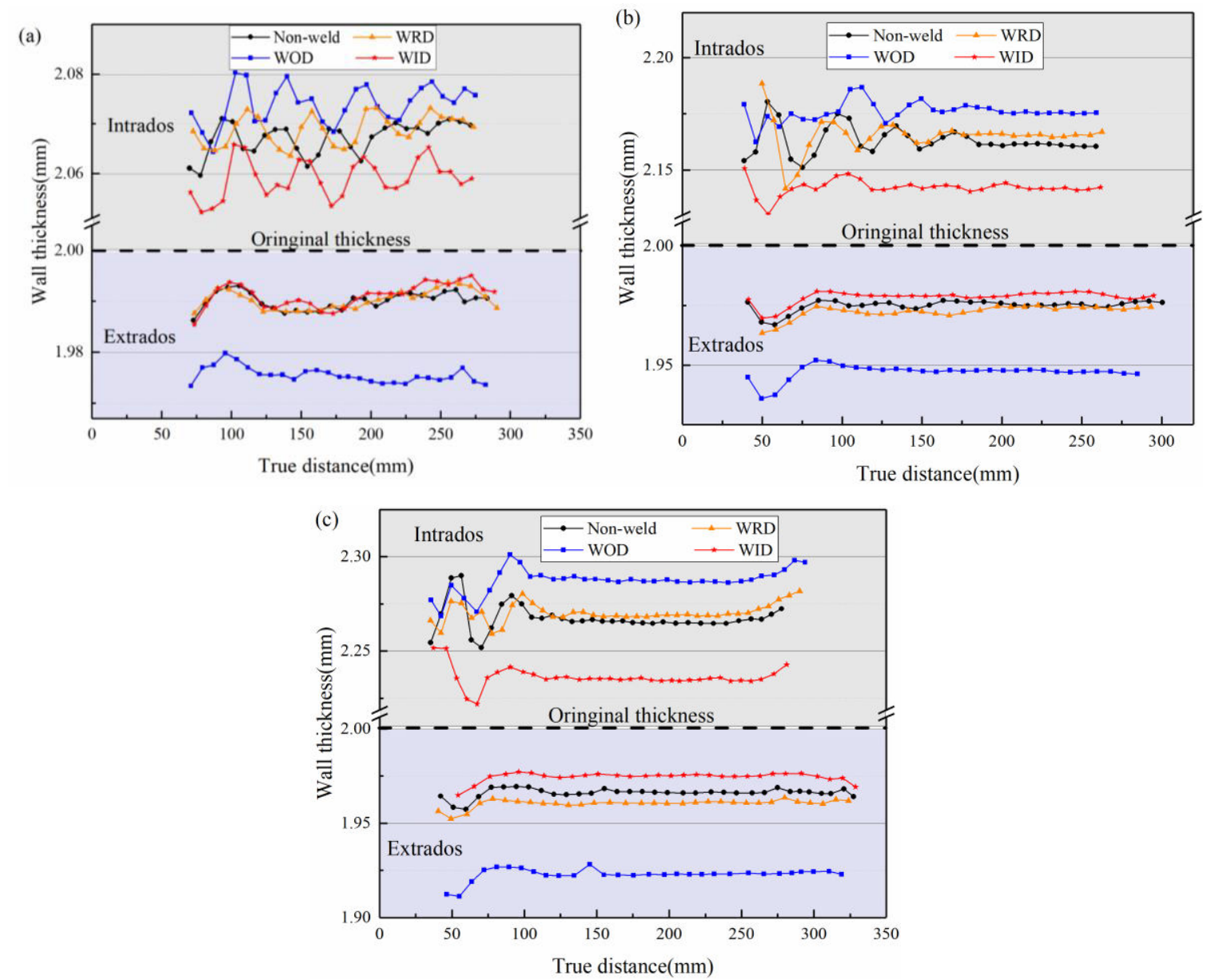

Fig. 17 Comparison of the wall thickness distribution with different weld position: (a) $\boldsymbol{U}=6$

$$
\mathrm{mm} \text {; (b) } \boldsymbol{U}=10 \mathrm{~mm} \text {; (c) } \boldsymbol{U}=14 \mathrm{~mm}
$$

To explain the evolution law of wall thickness distribution of welded tube with the position of weld, the theory of strain neutral layer shift and the phenomenon of cross-sectional distortion would be introduced. When the weld is located at the outside of bending direction, it can be deduced that the strain neutral layer would tend to shift from the intrados to extrados according to Eq. (20). Thus the wall thickness thickening in the intrados of bent tube would be promoted. Regardless of the circumferential strain, the tangential tensile strain of extrados of bent tube is approximately equal to the strain in the thickness direction of bent tube. Considering that the cross-sectional distortion rate $\gamma$ of welded tube with outside weld is less than that with inside weld during the free bending process, the excessing thinning of extrados of welded tube with outside weld could be determined. Similarly, the strain neutral layer would tend to shift from the extrados to intrados according to Eq. (20) when the weld is located at the inside of bending direction. The wall thickness thickening in the intrados of bent tube would be suppressed. Furthermore, the wall thickness thinning of extrados of bent tube would also be suppressed due to the larger cross-sectional distortion rate $\gamma$. When the weld is located 
at the right-side of bending direction, there is almost no plastic deformation in the weld zone and the bending deformation behavior of welded tube is similar to that of non-welded tube. Therefore, the wall thickness distribution of intrados and extrados of welded tube is consistent with that of non-welded tube.

\section{Conclusion}

In this paper, the influence of weld on the deformation behavior of welded tube during free bending process was sufficiently explored. The constitutive model of welded tube was established by hardness test and uniaxial tensile test. The influence of weld position on the $\boldsymbol{U}-\boldsymbol{R}$ relationship, cross-sectional distortion and wall thickness distribution was analyzed. The main findings were summarized in the following:

(1) The material strength in the weld zone of welded tube is significantly higher than that in the parent zone. The mechanical properties and constitutive models of weld zone and parent zone are considered and modeled separately.

(2) The position of weld has a significant influence on the $\boldsymbol{U}-\boldsymbol{R}$ relationship. When the weld of welded tube is located at the inside, outside and right-side of bending direction respectively, the corresponding bending radius decreases in sequence. In the free bending process of welded tube, the influence of weld position on the shape of bent tube needs to be considered.

(3) When the weld is located at different positions, the evolution law of the cross-sectional distortion rate $\gamma$ of welded tube with the deflection $\boldsymbol{U}$ of bending die is different. And the cross-sectional distortion rate $\gamma$ of welded tube is the smallest when the weld is arranged on the right-side of bent tube.

(4) The thickening of wall thickness of intrados and thinning of wall thickness of extrados of bent tube would be suppressed when the weld is located at the inside of bending direction and the uniformity of thickness distribution of welded tube could be improved. Therefore, to improve the forming quality and axis dimensional accuracy of welded tube in the free bending process, the weld position needs to be carefully considered.

\section{Acknowledgments}

The authors would like to acknowledge the funding support to this research from the Opening Project of State Key Lab of Digital Manufacturing Equipment \& Technology (No. 
DMETKF2021004), the National Natural Science Foundation of China (Nos: 52105360, U1937206), Jiangsu Province Key Research and Development Project (No.BE2019007-2), Fundamental Research Funds for the Central Universities (No. NS2021046), Ningbo "science and technology innovation 2025" major special project (No.2020Z078) and Youth Fund of Jiangsu Province Natural Science Foundation (No.BK20210310). 


\section{References:}

1. H Song, W Xie, S Zhang, W Jiang, L Lăzărescu, D Banabic. (2021). Granular media filler assisted push bending method of thin-walled tubes with small bending radius. INT J MECH SCI, 198, 106365. doi: https://doi.org/10.1016/j.ijmecsci.2021.106365

2. M Zhan, K Guo, H Yang. (2016). Advances and trends in plastic forming technologies for welded tubes. CHINESE J AERONAUT, 29(2), 305-315. doi: https://doi.org/10.1016/j.cja.2015.10.011

3. YX Zhu, W Chen, WB Tu, Y Guo, L Chen. (2020). Three-dimensional finite element modeling of rotary-draw bending of copper-titanium composite tube. The International Journal of Advanced M anufacturing Technology, 106(5), 2377-2389. doi: 10.1007/s00170-019-04781-0

4. TV Lukassen, E Gunnarsson, S Krenk, K Glejbøl, A Lyckegaard, C Berggreen. (2019). Tension-be nding analysis of flexible pipe by a repeated unit cell finite element model. MAR STRUCT, 64, 401-420. doi: https://doi.org/10.1016/j.marstruc.2018.09.010

5. KW Kim, MK Kim, WY Cho. (2019). An analytical model of roll bending steel pipe formed by $t$ hree rollers. The International Journal of Advanced Manufacturing Technology, 104(9), 4039-4048. doi: 10.1007/s00170-019-04183-2

6. H YANG, H LI, Z ZHANG, M ZHAN, J LIU, G LI. (2012). Advances and Trends on Tube Bending Forming Technologies. CHINESE J AERONAUT, 25(1), 1-12. doi: https://doi.org/10.1016/S1 000-9361(11)60356-7

7. P Gantner, DK Harrison, AK De Silva, H Bauer. (2007). The development of a simulation model and the determination of the die control data for the free-bending technique. Proceedings of the I nstitution of Mechanical Engineers, 221(B2), 163-171

8. J Wu, Z Zhang, Q Shang, F Li, Y Wang, Y Hui, H Fan. (2017). A method for investigating the springback behavior of 3D tubes. INT J MECH SCI, 131-132, 191-204. doi: https://doi.org/10.101 6/j.ijmecsci.2017.06.047

9. N Beulich, P Craighero, W Volk. (2017). FEA Simulation of Free-Bending - a Preforming Step i $\mathrm{n}$ the Hydroforming Process Chain. Journal of Physics: Conference Series, 896, 12063. doi: 10.10 88/1742-6596/896/1/012063

10. Y Zhou, P Li, M Li, L Wang, S Sun. (2018). Residual stress and springback analysis for 304 stainless steel tubes in flexible-bending process. The International Journal of Advanced Manufacturin g Technology, 94(1), 1317-1325. doi: 10.1007/s00170-017-0993-7

11. Z Zhang, J Wu, Q Shang, F Li, X Zhan. (2018). Investigation to Forming and Springback of Spatial Tubes in Bending-Twisting Process. Aeronautical Manufacturing Technology 61(16), 26-31. do i: $10.16080 /$ j.issn1671-833x.2018.16.026

12. X Guo, H Xiong, Y Xu, AA El-Aty, Y Ma, Y Zhao, S Zhang. (2018). U-R relationship predictio$\mathrm{n}$ method for aluminum alloy circular tube free-bending process based on sensitivity analysis of material parameters. The International Journal of Advanced Manufacturing Technology, 99(5), 196 7-1977. doi: 10.1007/s00170-018-2614-5

13. W Wei, H Wang, H Xiong, X Cheng, J Tao, X Guo. (2020). Research on influencing factors and laws of free-bending forming limit of tube. The International Journal of Advanced Manufacturing Technology, 106(3), 1421-1430. doi: 10.1007/s00170-019-04692-0

14. N Ren, M Zhan, H Yang, ZY Zhang, YT Qin, HM Jiang, KS Diao, XP Chen. (2012). Constraini- 
ng effects of weld and heat-affected zone on deformation behaviors of welded tubes in numerical control bending process. J MATER PROCESS TECH, 212(5), 1106-1115. doi: https://doi.org/10.1 016/j.jmatprotec.2011.12.023

15. N Ren, H Yang, M Zhan, Z Zhang, Y Qin, H Jiang, K Diao, X Chen. (2013). Strain distribution characteristics of welded tube in NC bending process using experimental grid method. The International Journal of Advanced Manufacturing Technology, 66(5), 635-644. doi: 10.1007/s00170-012-4 $354-2$

16. H Liu, Y Liu, P Zhang, X Du. (2020). Effect of weld zone and corner with cold bending effect o $\mathrm{n}$ wrinkling of rectangular welded tube in rotary draw bending. THIN WALL STRUCT, 157, 107 115. doi: https://doi.org/10.1016/j.tws.2020.107115

17. M Zhan, L Xing, PF Gao, F Ma. (2019). An analytical springback model for bending of welded tube considering the weld characteristics. INT J MECH SCI, 150, 594-609. doi: https://doi.org/10.1 016/j.ijmecsci.2018.10.060

18. A Khalfallah. (2014). Experimental and numerical assessment of mechanical properties of welded tubes for hydroforming. Materials \& Design (1980-2015), 56, 782-790. doi: https://doi.org/10.1016/j. matdes.2013.11.051

19. L Xing, M Zhan, PF Gao, F Ma. (2018). A method for establishing a continuous constitutive model of welded metals. Materials Science and Engineering: A, 718, 228-240. doi: https://doi.org/10. 1016/j.msea.2018.01.062

20. A Omar, A Tewari, K Narasimhan. (2020). Effect of bulge ratio on the deformation behaviour and fracture location during welded steel tube hydroforming process. Results in Materials, 6, 100096. doi: https://doi.org/10.1016/j.rinma.2020.100096

21. Y Jang, Y Lee, M Song, D Han, N Kim, H Lee. (2021). Evaluation of ductile fracture in welded tubes with tensile, hardness, flaring tests. INT J MECH SCI, 210, 106745. doi: https://doi.org/10. 1016/j.ijmecsci.2021.106745

22. H Liu, Y Liu. (2021). Cross section deformation of heterogeneous rectangular welded tube in rotary draw bending considering different yield criteria. J MANUF PROCESS, 61, 303-310. doi: https: //doi.org/10.1016/j.jmapro.2020.11.015 


\section{Statements \& Declarations}

\section{Funding:}

This work was supported by the Opening Project of State Key Lab of Digital Manufacturing Equipment \& Technology (No. DMETKF2021004), the National Natural Science Foundation of China (Nos: 52105360, U1937206), Jiangsu Province Key Research and Development Project (No.BE2019007-2), Fundamental Research Funds for the Central Universities (No. NS2021046), Ningbo "science and technology innovation 2025" major special project (No.2020Z078) and Youth Fund of Jiangsu Province Natural Science Foundation (No.BK20210310).

\section{Competing Interests:}

The authors have no relevant financial or non-financial interests to disclose.

\section{Author Contributions:}

All authors contributed to the study conception and design. Material preparation, data collection and analysis were performed by Cheng Cheng, Chao Pan, Xueshan Bai. The first draft of the manuscript was written by Chunmei Liu and Xunzhong Guo. All authors commented on previous versions of the manuscript. All authors read and approved the final manuscript. 


\section{List of Figures}

Fig. 1 Schematic diagram of three-dimensional free bending

Fig. 2 Geometry parameters of welded tube during free bending process

Fig. 3 Hardness experiment of the welded tube

Fig. 4 Microhardness distribution in the weld zone and parent zone

Fig. 5 Uniaxial tensile specimens: (a) specimen taken along the axial direction; (b) geometrical dimension

Fig. 6 The flow stress-strain curves of welded tube

Fig. 7 Stress distribution of mixed uniaxial tensile specimen

Fig. 8 Three-axial free bending forming equipment

Fig. 9 Free bending experiments of welded tube with different weld position: (a) outside of bent tube; (b) inside of bent tube; (c) right-side of bent tube

Fig. 10 FE model of free bending of welded tube

Fig. 11 Comparison of the experimental and simulation bent tubes: (a) experimental and simulation bent tube with weld; (b) simulation bent tube without weld

Fig. 12 Wall thickness distribution of welded and non-welded tubes

Fig. $13 \boldsymbol{U}$ - $\boldsymbol{R}$ relationship of welded tube and non-welded tube: (a) experimental bent tube; (b) $\boldsymbol{U}-\boldsymbol{R}$ relationship

Fig. 14 Schematic diagram of measuring cross-sectional distortion rate

Fig. 15 Cross-sectional distortion rate of the bent tube under different deflection $\boldsymbol{U}$

Fig. 16 Cross-sectional deformation of bent tube

Fig. 17 Comparison of the wall thickness distribution with different weld position: (a) $\boldsymbol{U}=6$ $\mathrm{mm}$; (b) $\boldsymbol{U}=10 \mathrm{~mm}$; (c) $\boldsymbol{U}=14 \mathrm{~mm}$ 


\section{List of Tables}

Table 1 Definition of every symbol

Table 2 Mechanical property parameters in different zones 